\title{
Serum Paraoxonase-1 Activity in Rheumatoid Arthritis Patients as a Risk Factor for Cardiovascular Comorbidity
}

\author{
Fatemah A. El-Shabacy ${ }^{1}$, Sherry K. Abd El-Rahman ${ }^{1}$, \\ Amal El-Maghraby², Eman M. Aissa ${ }^{3}$, Eman R. Amer ${ }^{3}$ \\ Departments of Rheumatology and Rehabilitation ${ }^{1}$, Internal Medicine ${ }^{2}$, Clinical Pathology ${ }^{3}$, \\ Benha Teaching Hospital, Benha; Egypt
}

\begin{abstract}
Background: Cardiovascular disease is a leading cause of morbidity and mortality in rheumatoid arthritis (RA) patients through progressive atherosclerosis. Inflammation plays a crucial role in atherogenesis. Paraoxonase-1 (PON1) has important role in decreasing susceptibility of LDL to lipid peroxidation and prevent or at least limits the oxidation of HDL which play a role in decreasing the susceptibility to atherosclerosis. Aim of the study: To estimate serum paraoxonase-1 (PNO1), in rheumatoid arthritis patients and its correlation - if any to disease activity and lipid profile. Methods: Sixty rheumatoid arthritis patients, attending the rheumatology department at Benha teaching hospital and thirty healthy volunteers were included in this study. Both groups were subjected to full history taking, clinical examination, laboratory assessment of serum paraoxinase-1 level, lipids profile, CBC, ESR and CRP. Results: The mean serum PNO1 level in RA patients was $(41.53 \pm 31.79 \mathrm{U} / \mathrm{ml})$ and this was highly significantly lower than its level in control group $(177 \pm$ $40.77 \mathrm{U} / \mathrm{ml})(\mathrm{p}<0.001)$. Correlations between this level and different laboratory and clinical parameters showed significant negative correlations with ESR, CRP, DAS-28 score, cholesterol and LDL. While serum PON-1 shows significant positive correlation with HDL. ROC curve was obtained to assess for the validity of paraoxinase- 1 in prediction of cardiovascular risk in severly active RA patients, it showed that paraoxinase -1 at a cut off value $\leq 26$ can significantly predict cardiovascular risk in severly active RA patients, with sensitivity $76.5 \%$ and specificity $72.1 \%$. Conclusion: low serum paraoxinase-1 activity is a real risk factor for cardiovascular disease in RA patients, as it is significantly negatively correlated with RA disease activity. [Egypt J Rheumatology \& Clinical Immunology, 2015; 3(2): 133-140]
\end{abstract}

\section{INTRODUCTION}

Cardiovascular disease is a leading cause of mortality in rheumatoid arthritis (RA) patients. Accelerated atherosclerosis plays a crucial role in cardiovascular disease reported in $\mathrm{RA}^{1}$.

Inflammation plays a major role in atherogenesis by local cellular mechanisms or humoral consequences. In most cases inflammation and endothelial dysfunction are triggered by cardiovascular risk factors; hypercholesterolemia, hypertension, smoking or DM. Inflammation precedes atherosclerotic changes that occur in autoimmune diseases as rheumatoid arthritis is independent from conventional risk factors ${ }^{2}$.

Cholesterol efflux activity and reverse cholesterol transport are the classic functions of high density lipoprotein (HDL) yet increasing evidence shows that additional cardio-protective antioxidant and anti-inflammatory functions of HDL exist. Isolated HDL can reduce low density lipoprotein (LDL)-associated cholesterol ester hydroperoxides ${ }^{3}$. HDL facilitates numerous anti-inflammatory activities and antioxidant activities mediated by Apo lipoprotein
A1 (Apo A1) within the core lipoprotein particle and an assortment of HDL-associated protein ${ }^{4}$. LDL particles modified by free radicals are believed to play a critical role in atherosclerosis by stimulating intimal monocyte infiltration and smooth muscle cell migration and proliferation ${ }^{5}$.

Paraoxonase-1 (PON-1) is an enzyme synthesized by the liver it is a major antiatherosclerotic component of the high-density lipoprotein (HDL). The PON1 gene (on chromosome 7 ) is activated by PPAR- $\gamma$, which increases synthesis and release of paraoxonase 1 enzyme from the liver hence reducing atherosclerosis ${ }^{6}$.

PON1 is in close association with HDL function, it has been shown to decrease the susceptibility of LDL to lipid perioxidation which play a major role in the development of atherosclerosis ${ }^{6}$.

It is supposed that LDL particles can be protected from free radical oxidation by HDL-linked enzyme PON1, thus it has a major protective anti atherosclerotic function. It is present in different tissues; liver, kidney, intestine and also in the serum. Serum PON1 activity and concentration is decreased in patients with cardiovascular diseases and other 
pathologies that increase the risk of vascular disorders $^{7}$

Aim of the study: To estimate serum paraoxonase-1 (PNO1) level, in patients with rheumatoid arthritis and its correlation-if any with disease activity and lipids profile.

\section{PATIENTS AND METHODS}

This is a case control cross sectional study that included sixty rheumatoid arthritis patients attending the rheumatology department Benha teaching hospital, diagnosed according to American College of Rheumatology (ACR 2010) and European League against Rheumatism (EULAR) RA revised criteria ${ }^{8}$. In addition to thirty healthy volunteers with matched age and sex as a control group.

\section{Exclusion criteria:}

- Those suffering from renal diseases, hypertension, ischemic heart disease and DM.

- $\quad$ Smokers.

- $\quad$ Patients on statins or other lipid lowering agents.

All patients were subjected to the following:

Complete history taking, full clinical general and rheumatological examinations, assessment of disease activity using the disease activity score (DAS-28) ${ }^{(9)}$ ,Written informed consents were obtained from all patients and controls.

\section{Laboratory test:}

- CRP.

- RF

- ESR.

- Estimation of liver enzymes, blood urea, serum creatinine.

- Random blood glucose.

- Lipid profile: LDL cholesterol. HDL, cholesterol and serum triglyceride.

Assay of serum enzyme paraoxonase-1 activity. Human paraoxanase-1 (PON-1):

Human paraoxanase-1 enzyme was measured by ELISA method; from commercially available kit WKFA (Med. supplies) from USA.

\section{Principles of the assay:}

Purified human PON antibody coated micro titer plate wells to make solid phase antibody, then PON was added to the wells, combined PON which with enzyme labeled, became antibody- antigen -enzyme antibody complex after washing completely, substrate was added, substrate became blue color. HRP enzyme catalyzed reaction was terminated by the addition of a sulphuric acid solution and the color change was measured spectrophotometrically at a wave length of $450 \mathrm{~nm}$. The concentration of PON in the sample is then determined by comparing the O.D. of the sample to standard curve.

Highly sensitive C-reactive protein (CRP) assay: was measured by ELISA method: from commercially available kit from Chemux Bioscience. Inc. Bios from USA.

Measurement of serum triglyceride:

Triglyceride was measured by enzymatic colorometric lipoprotein lipase method using commercially available kit from Spinreact; S.A.U.

\section{Measurement serum cholesterol:}

Cholesterol was measured by enzymatic colorometric cholesterol oxidase method using commercially available kit from spin react: S. A.U.

\section{Measurement of HDL cholesterol:}

HDL was measured by direct enzymatic colorometric method using commercially available kit from Spinreact: S. A.U. First elimination of lipoprotein no HDL, Second measurement of HDL by cholesterol oxidase method.

Measurement of LDL cholesterol:

LDL was measured by Fridrechson"s equation;

$$
\mathrm{LDL}=\text { total cholesterol }-\left(-\frac{T G}{5}+\mathrm{HDL}\right) .
$$
analyzed.

All data will be tabulated and statistically

\section{Statistical Analysis:}

The collected data were tabulated and analyzed using SPSS version 16 soft ware (Spss Inc, Chicago, ILL Company). Data were expressed as mean \pm standard deviation, median and inter quartile range (IQR) and range. Student"t" test, Mann Whitney U test (MWU) and Spearman's correlation coefficient (rho) were used as tests of significance. ROC curve analysis was used to detect cut off value of Paraoxinase with optimum sensitivity and specificity in prediction of high grade RA. The accepted level of significance in this work was stated at $0.05(\mathrm{P} \leq 0.05$ was considered significant).

\section{RESULTS}

The study included sixty RA patients recruited from outpatient clinic of rheumatology department Benha teaching hospital; all were females (100\%) and sero-positive for rheumatoid factor. Their age ranged 
from 40 to 52 years with mean $(42.90 \pm 8.83)$, and their disease duration ranged from 1-20 years with mean (8.9 \pm 5.7$)$. In addition to thirty apparently healthy volunteers with matched age and sex as a control group. Clinical evaluation of the patients revealed that their disease activity score (DAS- 28) was ranging from 1.8 to 6.0 , mean $(4.07 \pm 1.2), 30 \%$ of the patients had low DAS, $45 \%$ had moderate DAS, and $25 \%$ had severe DAS (Table 1 and Figure 1).

ECG was performed for RA patients and interpreted by internist, showed no abnormality except in two patients whom showed P-pulmonale and one extra-systole.

Laboratory estimation of serum lipid profile in RA patients and controls revealed that cholesterol and LDL were significantly higher in RA patients than controls $(\mathrm{p}<0.001)$ for cholesterol and $(<0.05)$ for LDL. The mean level of cholesterol and LDL in RA patients was $(220.45 \pm 41.62)$ and $(155.07 \pm 33.51)$ respectively. As regard HDL it was highly significantly lower in RA patients than controls $(\mathrm{p}<0.001)$ and its mean level in RA patients was

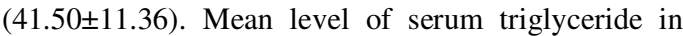
RA patients was $(89.06 \pm 31.31)$ with non significant difference when compared with that of control group. Paroxonase-1activity was estimated in RA patients and controls, its mean value was $(41.53 \pm 31.79)$ among RA patients and it was highly significantly lower than its value in control group $(177 \pm 40.77)(\mathrm{p}<0.001)$. Acute phase reactant ESR and CRP was significantly elevated in RA patients compared to controls, the mean level of ESR and CRP in RA patients was $(51.0 \pm 24)$ and $(16.95 \pm 9.78)$ respectively $(\mathrm{p}<0.01)$ (Table 2)

Correlation between Serum paraoxinase-1 in RA patients and different laboratory and clinical parameters using Spermans correlation test, there were significant negative correlations between PON-1 with each of: ESR, CRP, disease activity score DAS-28, cholesterol and LDL. While it showed significantly positive correlation with HDL level (Table 3 and Figures $2 \& 3$ ).

Roc curve was obtained to study the validity of paraoxinase- 1 in prediction of cardiovascular risk and high disease activity in RA patients, it showed that paraoxinase- 1 at a cut off value $\leq 26$ can significantly predict cardiovascular risk and severely active disease in RA patients, with a sensitivity $76.5 \%$, specificity $72.1 \%$, PPV\% 52, NPV\% 88.6, the area under the curve $(\mathrm{AUC})=0.75$ with $95 \% \mathrm{CI}=0.63-0.88$ $(\mathrm{p}<0.05)$ (Table 4, Figures $4 \& 5)$.

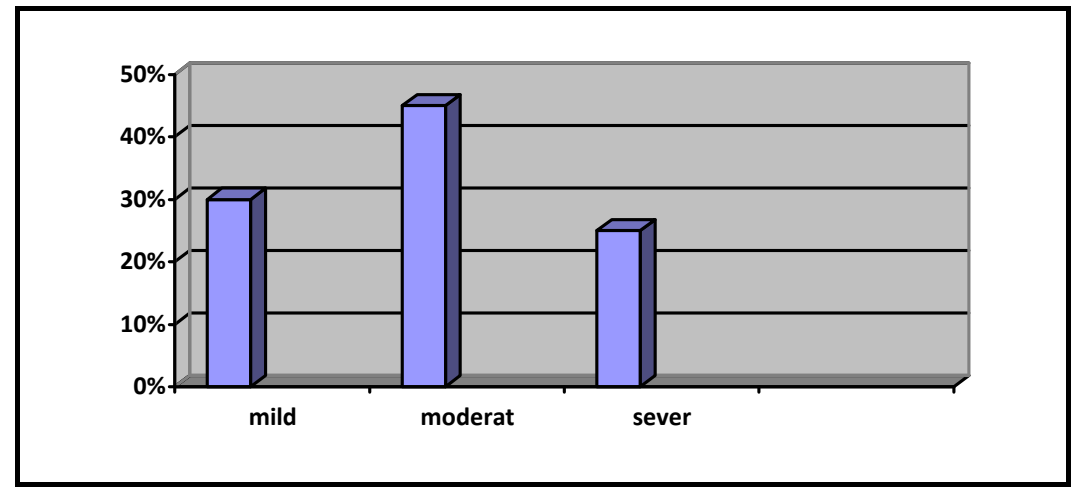

Figure 1. DAS-28 score among RA patients.

Table 1. Demographic and Clinical data of RA patients group

\begin{tabular}{lcc}
\hline \multicolumn{1}{c}{ Variable } & Mean \pm SD & Range \\
\hline Disease duration $(\mathrm{y})$ & $8.9 \pm 5.7$ & $1-20$ \\
NTJ & $5.6 \pm 5.1$ & $0-20$ \\
NSJ & $1.5 \pm 2.1$ & $0-10$ \\
DAS & $4.07 \pm 1.2$ & $1.8-6.0$ \\
\hline
\end{tabular}

$\mathrm{TJC}=$ tender joint count, $\mathrm{SJC}=$ swollen joint count, $\mathrm{DAS}=$ disease activity score 
Table 2. Comparison between the studied groups regarding laboratory data.

\begin{tabular}{|c|c|c|c|c|c|c|}
\hline \multirow{2}{*}{ Variable } & \multicolumn{2}{|c|}{ RA patients $(n=60)$} & \multicolumn{2}{|c|}{ Control $(n=30)$} & \multirow{2}{*}{$\begin{array}{c}\text { “Z" of } \\
\text { MWU test }\end{array}$} & \multirow{2}{*}{$\mathbf{p}$} \\
\hline & Mean & \pm SD & Mean & \pm SD & & \\
\hline T. cholesterol mg\% & 220.45 & 41.62 & 190.60 & 11.62 & 3.62 & $<0.001(\mathrm{HS})$ \\
\hline TG $\mathrm{mg} \%$ & 89.06 & 31.31 & 85.40 & 6.35 & 0.04 & $0.96(\mathrm{NS})$ \\
\hline HDL mg\% & 41.50 & 11.36 & 53.10 & 4.99 & 4.57 & $<0.001$ (HS) \\
\hline LDL mg\% & 155.07 & 33.51 & 143.50 & 11.44 & 2.12 & $0.03(\mathrm{~S})$ \\
\hline CRP mg\% & 16.95 & 9.78 & 3.20 & 1.82 & 6.15 & $<0.001(\mathrm{HS})$ \\
\hline ESR $1^{\text {st }} \mathrm{h}$ & 51.0 & 24.6 & 10.0 & 2.0 & ------- & $<0.001(\mathrm{HS})$ \\
\hline Paroxonase-1 (U/ml) & 41.53 & 31.79 & 177.00 & 40.77 & 7.68 & $<0.001(\mathrm{HS})$ \\
\hline
\end{tabular}

$\mathrm{ESR}=$ erythrocyte sedimentation rate, $\mathrm{CRP}=\mathrm{C}$ - reactive protein. $\mathrm{TG}=$ triglyceride, $\mathrm{HDL}=$ high density lipoprotein, $\mathrm{LDL}=$ low density lipoprotein $\mathrm{NS}=$ non significant, $\mathrm{s}=$ significant, $\mathrm{HS}=$ highly significant .

Table 3. Correlation between paraoxanase-1 level and the studied variables in RA patients.

\begin{tabular}{llcccc}
\hline & \multicolumn{5}{c}{ Paraoxinase-1 } \\
\cline { 3 - 6 } & & \multicolumn{2}{c}{ Patient group } & \multicolumn{2}{c}{ Control group } \\
\cline { 3 - 6 } & TC mg\% & $\mathbf{r}$ & $\mathbf{P}$ & $\mathbf{r}$ & P \\
\hline \multirow{2}{*}{ Lipid profile } & TG mg\% & -0.789 & $<0.001(\mathrm{HS})$ & -0.511 & $0.004(\mathrm{~S})$ \\
& HDL mg\% & -0.074 & $0.57(\mathrm{NS})$ & 0.122 & $0.52(\mathrm{NS})$ \\
& LDL mg\% & 0.859 & $<0.001(\mathrm{HS})$ & -0.224 & 0.23 (NS) \\
\hline CRP mg\% & & -0.768 & $<0.001(\mathrm{HS})$ & 0.340 & $0.066(\mathrm{NS})$ \\
ESR mg\% & & -0.408 & $0.001(\mathrm{HS})$ & -0.273 & $0.14(\mathrm{NS})$ \\
DAS-28 & & -0.610 & $<0.001(\mathrm{HS})$ & --- & --- \\
\hline
\end{tabular}

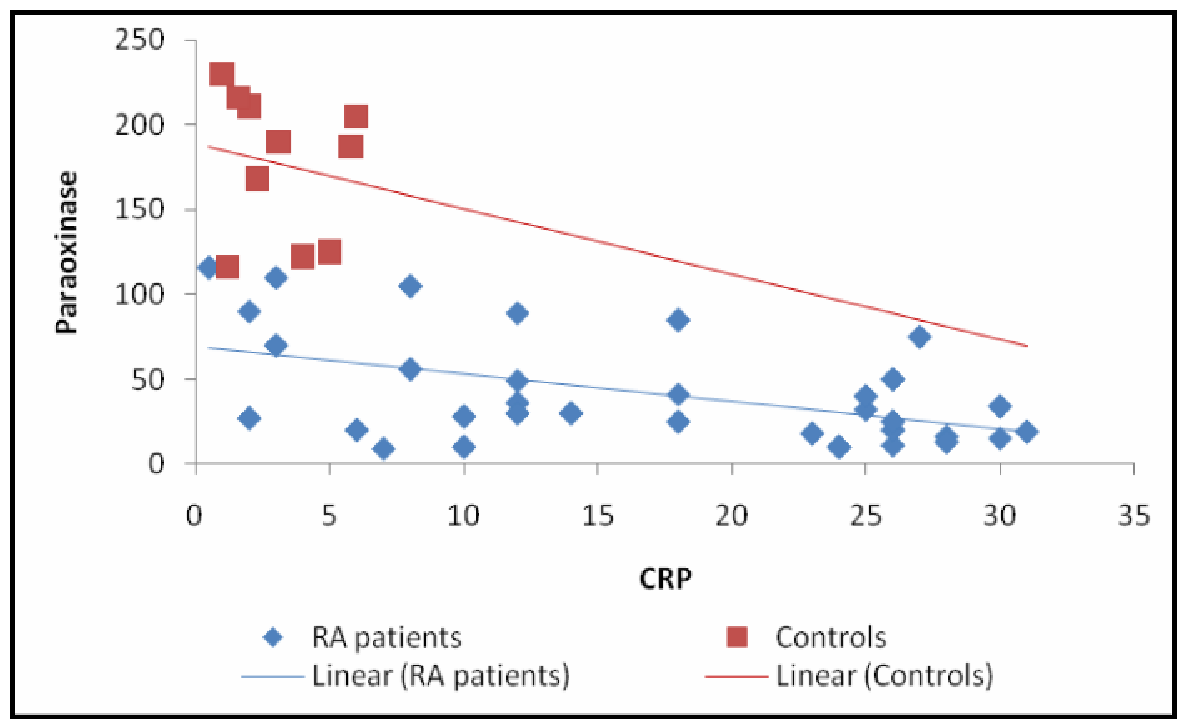

Figure 2. Correlation between serum paraoxinase-1 and CRP level. 
El-Shabacy, et al.: Serum paraoxonase-1 and cardiovascular comorbidity in patients with rheumatoid arthritis

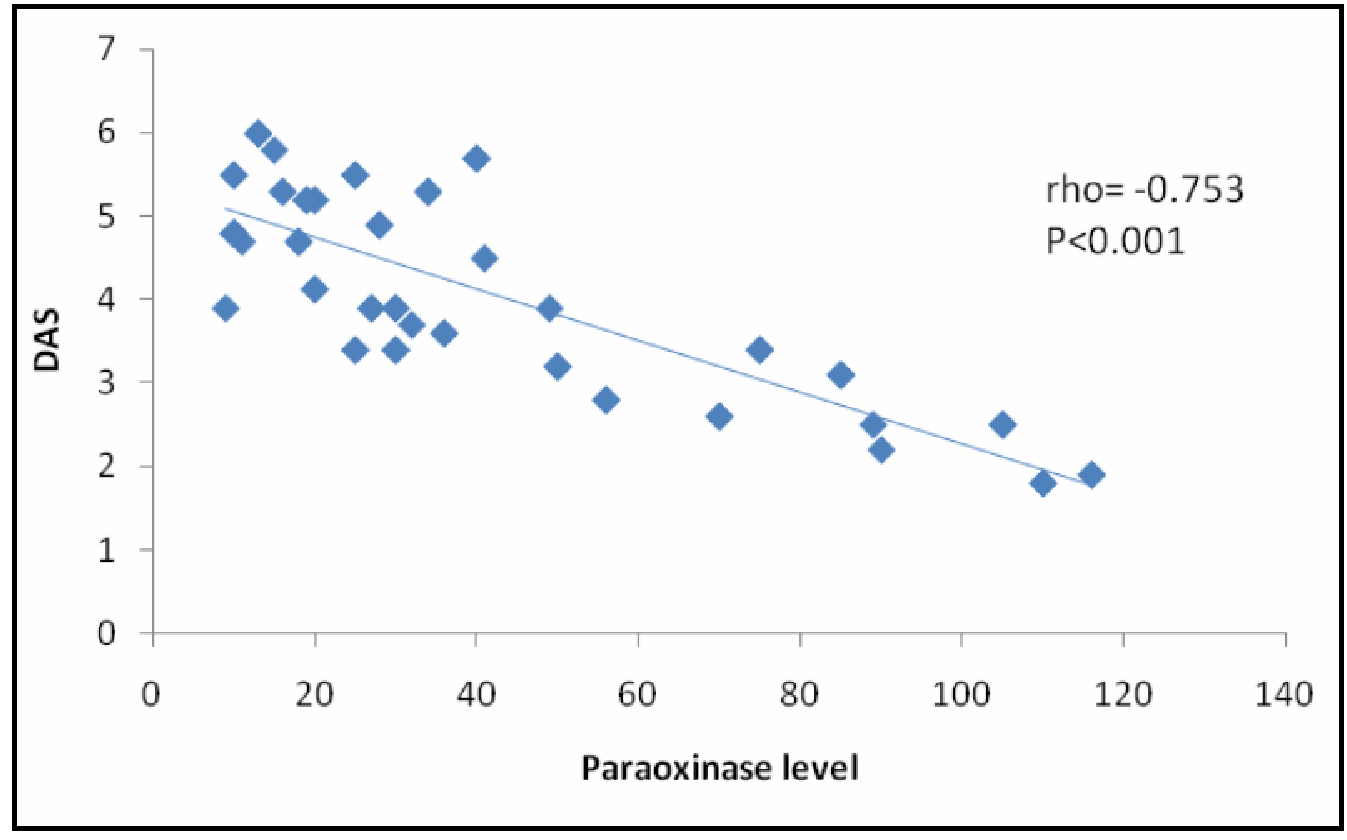

Figure 3. Correlation between serum paraoxinase-1 and DAS -28 in RA patients.

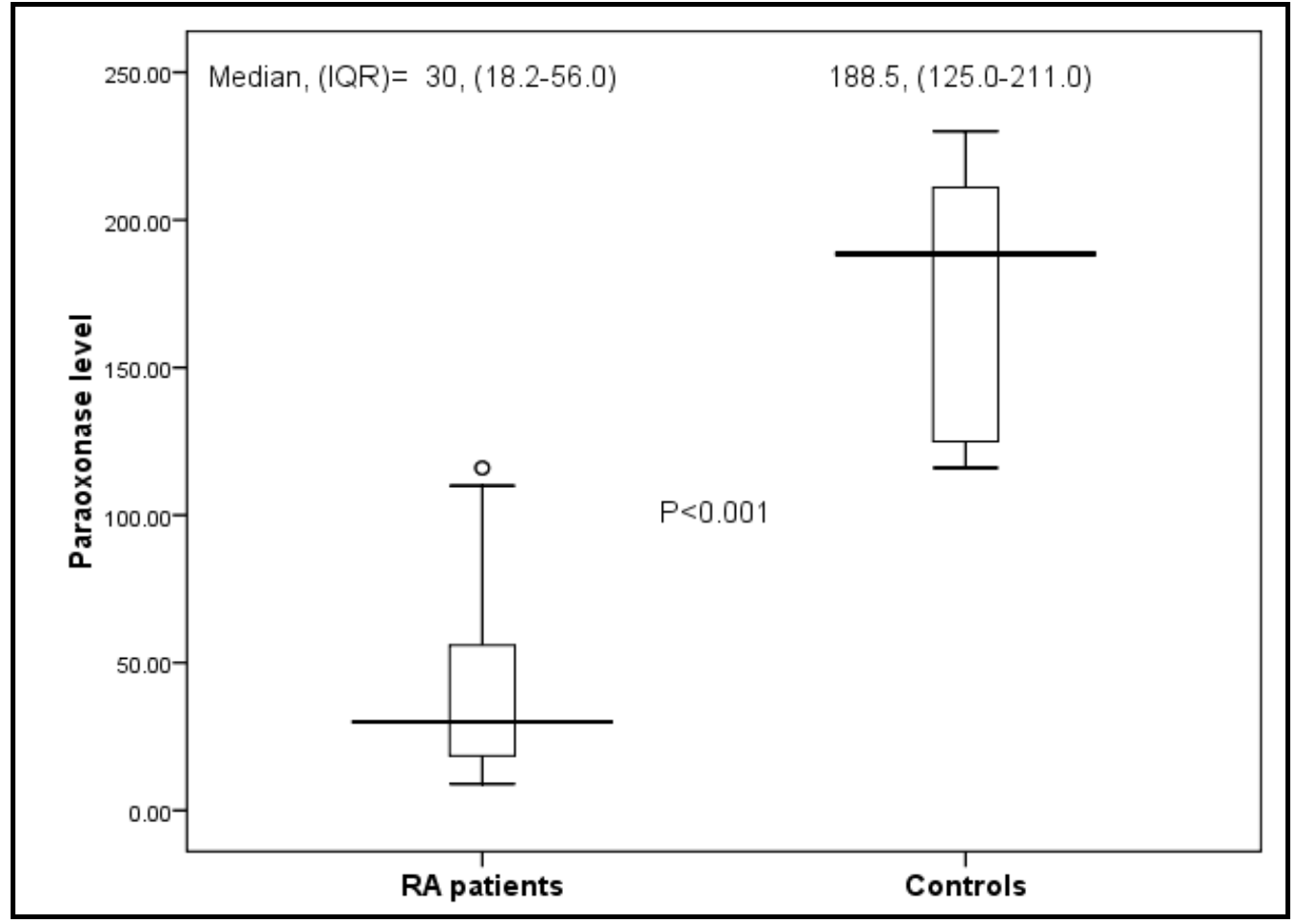

Figure 4. Box plot for median and IQR of paraoxanase-1 among the studied groups. 


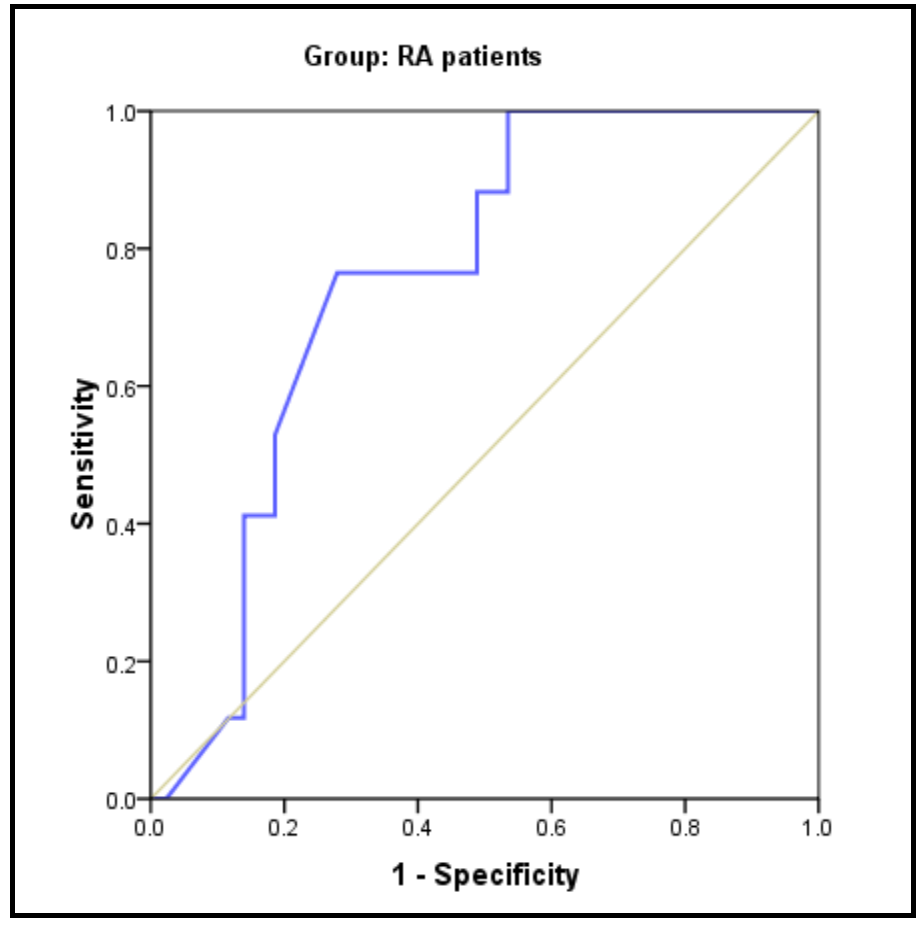

Figure 5. ROC curve for the validity of paraoxinase- 1 in prediction of cardiovascular risk in RA.

Table 4. Roc curve for the validity of paraoxinase - 1 in prediction of cardiovascular risk in severe RA.

\begin{tabular}{cccccccc}
\hline Cut off value & Sens\% & Spec\% & PPV\% & NPV\% & AUC & 95\% CI & P \\
\hline$\leq 26$ & $76.5 \%$ & $72.1 \%$ & $52 \%$ & $88.6 \%$ & 0.75 & $0.63-0.88$ & $0.002(\mathrm{~S})$ \\
\hline
\end{tabular}

\section{DIsCussion}

Paraoxonase-1 (PON-1) is a HDL-associated protein of 354 amino acids. It is synthesized in the hepatocytes and it has been reported to be an important contributor to the antioxidant and antiinflammatory activity of HDL. PON-1 impedes oxidative modification of LDL; PON-1 serum activity is related to systemic lipid oxidative stress and prospective cardiovascular risk ${ }^{10}$.

The paraoxonase gene family in humans is located in chromosome 7, it includes three members: PON-1, PON-2, PON-3, paraoxonase-1 (PON-1) is mainly associated with a high density lipoprotein (HDL) molecule a small amount of this enzyme is also bound to very low density lipoprotein (VLDL) and postprandial chylomicrons ${ }^{11}$.
Allele frequencies for PON-1 gene that influence enzyme concentration as well as activity differ greatly among ethnic groups and data from several studies showed ethnic variations in the interpretation of cardiovascular disease associated with PON-1 polymorphism. Low PON-1 activity has been constantly linked with an increased risk of major cardiovascular events in the setting of secondary prevention of coronary artery disease. ${ }^{12}$

Studies of HDL of patients recovered from acute coronary syndrome revealed enhanced chlorotyrosine content, site specific PON-1 methionine oxidation and reduced PON-1 activity. HDL thus serves as scaffold upon which myeloperoxidase (MPO) (which is linked to inflammation, oxidative stress and atherosclerosis) can oxidize apolipoprotein A1 (Apo A1) of HDL impairing its atheroprotective function. While upon 
PON-1 binding to HDL it partially inhibits MPO activity and resume its atheroprotective function ${ }^{13}$.

In this study paroxonase- 1 was assessed in a group of sixty sero-positive RA patients and their matched controls, its mean value in RA group was $(41.53 \pm 31.79)$, that was highly significantly lower than its level in control group $(\mathrm{p}<0.001)$.

El-Banna et al. (2014) ${ }^{14}$ have conducted a study on rheumatoid arthritis patients that showed that there was a significant correlations between rheumatoid factor and anti CCP antibody (ACCPA) titers and decreased PON-1 activity- hence increased cardiovascular risk in those patients. This indicates a significant association between decreased antioxidant enzymes activity and the serum level of rheumatoid factor and ACCPA. The more the sero-positivity of rheumatoid arthritis patients to RF /ACCPA the more will be the disease activity and the decreased PON-1 activity hence increases the risk of atherosclerotic cardiovascular disease.

The current study estimated lipid profile in two groups RA patients and control group, and showed that cholesterol and LDL were significantly higher in RA patients than controls $(\mathrm{p}<0.001)$ for cholesterol and $(<0.05)$ for LDL. The mean level of cholesterol and LDL in RA patients was $(220.45 \pm 41.62)$ and (155.07 \pm 33.51$)$ respectively.

Interestingly, the HDL was highly significantly lower in RA patients than in control group $(p<0.001)$, its mean level in RA patients was $(41.50 \pm 11.36)$. This indicates a statistically significant cardiovascular risk factors in those patients. While there was no statistically significant difference between RA patients and their controls regarding serum triglyceride level, $(\mathrm{p}>0.05)$

In concordance to our study, Tanimoto and his colleagues proved that HDL which remodels structurally and functionally in rheumatoid arthritis might be less atheroprotective due to impairment of original HDL function; these alterations may explain the reported increase cardiovascular morbidity and mortality in rheumatoid arthritis patients ${ }^{15}$.

Again In agreement with the current study, Kobayashi et al. (2010) ${ }^{16}$ have conducted a wide scale study on large number of rheumatoid arthritis patients (195 patients) and a similar number of healthy volunteers as controls, with similar cardiovascular risk except for hypertension. Rheumatoid arthritis patients showed higher prevalence of atherosclerotic vessel disease compared to controls.

In the same way, Chales-Schoeman et al. $(2013)^{17}$ has assessed the cardiovascular risk in RA patients. Cardiovascular risk evidenced was proved by the presence of significant carotid atherosclerotic plaques assessed by carotid duplex and elevated lipid profile in rheumatoid arthritis patients. Importantly, those patients showed low plasma paraoxonase-1 activity suggesting relationship between low paraoxonase-1 activity and increased cardiovascular risk in those patients.

Moreover, In our study significant negative correlations were found between serum paraoxinase-1 level and different laboratory and clinical parameters of disease activity including ESR, CRP, DAS-28, also with cholesterol and LDL. Meanwhile, there is significant positive correlation between PON-1 activity and HDL. This indicates that the more the disease activity in RA patients (DAS-28) the less will be the PON-1 level i.e. the more the cardiovascular risk. These signify the importance of early and continuous remission induction in RA patients, as a main protective mechanism against the risk of cardiovascular insults in those patients.

Chales-Schoeman et al. $(2012)^{18}$ reported that the cholesterol efflux capacity of HDL is impaired in rheumatoid arthritis patients with high disease activity and this is correlated with systemic inflammation. In RA patients there is attenuation of HDL antioxidant capacity, independent of HDL / cholesterol levels may suggest a mechanism by which active rheumatoid arthritis contributes to increase cardiovascular risk.

The antioxidant activity of high density lipoprotein (HDL) is largely due to the paraoxonase (PON-1) this effect of HDL results in decreasing low density lipoprotein (LDL). Lipid peroxidation is maintained for longer than that of antioxidant vitamins and could therefore be more protective..$^{19,20}$

ROC curve for the validity of paraoxinase- 1 in prediction of increased cardiovascular risk and RA disease activity showed that paraoxinase- 1 at a cut off value $\leq 26$ can significantly predict increased cardiovascular risk and severe grade RA with sensitivity $76.5 \%$, specificity $72.1 \%$. So we concluded that, estimation of paraoxinase- 1 level in RA patients can be used as a measure to the possible cardiovascular risk in those patients. Paraoxinase-1 activity was significantly reduced in severely active RA patients -those are at great risk of cardiovascular disease than RA patients with inactive disease. Early and continuous control of RA disease activity is the corner stone of decreasing the cardiovascular risk in those patients.

\section{REFERENCES}

1. Wallberg-Jonsson S, Ohman M, Rantapa A, Dahlquist $\mathrm{S}$. Which factors are related to the presence of atherosclerosis in rheumatoid arthritis. Scand j Rheumatol. (2004); 33(6):373-9.

2. Profumo ED, Franco M, Buttari B, Masella R, Filesi C, Tosti ME, Scrivo R, Scarno A, Saso L, Rigano R. Biomarkers of subclinical atherosclerosis in patients with autoimmune disorders. Mediators Inflamm (2012); 503942. Epub Feb 22. 
3. Rye KA, Bursill CA, Lambert G, Tabet F, Barter PY. The metabolism and anti-atherogenic properties of HDL. J Lipid Res. (2009); 50:S195-S 200.

4. Besler $\mathrm{C}$ et al. Mechanisms underlying adverse effects of HDL on enoS. Activating pathway, in patients with coronary artery disease. J.Clin Invest. (2011); 121(7):2693-2708.

5. Rozek Is Ts, Hatsukami RY, Richter J, Ranchalis K, Nakajama LA, Mckenstry DA, Gortnes E, Boyko GD, Schellenberg CE, Furlong C, et al. The correlation of paraoxonase-1 (PON1) activity with lipid and lipoprotein levels differs with vascular disease status. J Lipid Res. (2005).46:1888-1895.

6. Mertens A, Holvet P. Oxidized LDL and HDL: antagonists in atherothrombosis. FASEB J (2001); Oct; 15 (12):2073-84.

7. Leviev IA, Righetti and James RW. Paraoxonase promoter polymorphism (T-107) and relative paraoxonase deficiency as determinants of risk of coronary artery disease. J.Mol.Med. (2001); 79:457-463.

8. Aletaha D. , Neogi T., Silman A. J., Funovits J. et al: 2010 rheumatoid arthritis classification criteria: an American College of Rheumatology/European League Against Rheumatism collaborative initiative study. Ann. Rheum. Dis. ; 69(9):1580-8.

9. Preveoo ML,Van't Hoh MA, Kuper HH, Van Leeuwen MA, Van de Putee LP, Van Riel PL(1995): Modified disease activity score include twenty-eight joint counts, development and validation in a prospective longitudinal study of patients with rheumatoid arthritis. Arthritis Rheum, 38:44-8.

10. Soran H, Younis NN, Charlton-Meny SV, Durringyon P. Variation in paraoxonase-1 activity and atherosclerosis. Curr Op in Lipidol. (2009); Aug, 20(4):265-74.

11. Rajkovic MG, Rumora L, Barisic K. The paraoxonase 1, 2 and 3 inhumans. Biochem Med (Zagreb) (2011); 21(2):122-30.

12. El-Lebedy D, Kafoury M, Abd-El Haleem L, Ibrahim A, et al. Paraoxonase-1 gene Q192R and
L55 M polymorphisms and risk of cardiovascular disease in Egyptian patients with type 2 diabetes mellitus. J Diabetes Metab Disord. (2009); Dec 20, 13(1):124.

13. Huang $\mathrm{Y}, \mathrm{Wu} Z$, Riwanto M, Gao S, Levison BS et al. Myeloperoxidase, paraoxonase-1 and HDL from a functional ternary complex. J Clin Invest. (2013); Sep; 123(9): 3815-28.

14. El-Banna H, Jiman-Fatani A. Anticyclic citrullinated peptide antibodies and paraoxonase-1 polymorphism in rheumatoid arthritis.BMC Muscloskelet Disord. (2014). Nov 19; 15:379.

15. Tanimota N, Kumon Y, Suehiro T, Ohkubo S, Ikeda Y, Nishiya K, Hashimoto K. Serum paraoxonase activity decreases in rheumatoid arthritis. Life Sci (2003); May 9; 72(25):2877-85.

16. Kobayashi H, Giles YT, Polak JF, Blumenthal RS et al. increased prevalence of carotid artery. Atherosclerosis. (2010); Apr; 3) Kobayashi H, Giles YT, Polak JF, Blumenthal RS et al. Increased prevalence of carotid artery. Atherosclerosis. (2010); Apr; 37(4): 730-9.

17. Chales-Schoeman C, Lee YY, Shahbazian A, Gorn ALL et al. Association of paraoxonase-1 gene polymorphism and enzyme activity with carotid plaque in rheumatoid arthritis. Arthritis Rheum (2013). Nov; 65(11): 2765-72.

18. Chales-Schoeman, Lee YY, Grijalva V, Amjadi S, Fitzgera $\mathbf{J}$ et al. Cholesterol efflux by high density lipoproteins is impaired in patients with active rheumatoid arthritis, Ann Rheum Dis. (2012) Jul;71(7):1157-62.

19. Mackness MI, Durringyon PN, Mackness B. The role of paraoxonase-1activity in cardiovascular disease: potential or therapeutic intervention. Cardiovasc Drugs (2004); 4(4):211-7.

20. Mackness B, Davies GK, Turkie W, Lee E, Robert DH, Hill E, Roberts C, Durringyon PN, Mackness MI. Paraoxonase status in coronary heart disease are activity and concentration more important than genotype? Thromb Vasc Biol (2001).Sep; 21(9):145-7. 